\title{
Hypothalamic Inflammation and Energy Balance Disruptions: Spotlight on Chemokines
}

\author{
Ophélia Le Thuc ${ }^{1,2,3}$, Katharina Stobbe', Céline Cansell', Jean-Louis Nahon', \\ Nicolas Blondeau ${ }^{1}$ and Carole Rovère ${ }^{1 *}$
}

${ }^{1}$ CNRS, Institut de Pharmacologie Moléculaire et Cellulaire, Université Côte d'Azur, Valbonne, France, ${ }^{2}$ Helmholtz Diabetes Center (HDC), German Center for Diabetes Research (DZD), Helmholtz Zentrum München, Neuherberg, Germany, ${ }^{3}$ Division of Metabolic Diseases, Technische Universität München, Munich, Germany

\section{OPEN ACCESS}

Edited by:

Hubert Vaudry,

University of Rouen, France

Reviewed by:

Gina Leinninger,

Michigan State University,

United States

Julie A. Chowen,

Hospital Infantil Universitario

Niño Jesús, Spain

*Correspondence:

Carole Rovère

rovere@ipmc.cnrs.fr

Specialty section:

This article was submitted to Neuroendocrine Science,

a section of the journal

Frontiers in Endocrinology

Received: 10 March 2017

Accepted: 27 July 2017

Published: 14 August 2017

Citation:

Le Thuc O, Stobbe K, Cansell C,

Nahon J-L, Blondeau N and

Rovère C (2017) Hypothalamic

Inflammation and Energy Balance

Disruptions: Spotlight on

Chemokines.

Front. Endocrinol. 8:197.

doi: 10.3389/fendo.2017.00197
The hypothalamus is a key brain region in the regulation of energy balance as it controls food intake and both energy storage and expenditure through integration of humoral, neural, and nutrient-related signals and cues. Many years of research have focused on the regulation of energy balance by hypothalamic neurons, but the most recent findings suggest that neurons and glial cells, such as microglia and astrocytes, in the hypothalamus actually orchestrate together several metabolic functions. Because glial cells have been described as mediators of inflammatory processes in the brain, the existence of a causal link between hypothalamic inflammation and the deregulations of feeding behavior, leading to involuntary weight loss or obesity for example, has been suggested. Several inflammatory pathways that could impair the hypothalamic control of energy balance have been studied over the years such as, among others, toll-like receptors and canonical cytokines. Yet, less studied so far, chemokines also represent interesting candidates that could link the aforementioned pathways and the activity of hypothalamic neurons. Indeed, chemokines, in addition to their role in attracting immune cells to the inflamed site, have been suggested to be capable of neuromodulation. Thus, they could disrupt cellular activity together with synthesis and/or secretion of multiple neurotransmitters/mediators involved in the maintenance of energy balance. This review discusses the different inflammatory pathways that have been identified so far in the hypothalamus in the context of feeding behavior and body weight control impairments, with a particular focus on chemokines signaling that opens a new avenue in the understanding of the major role played by inflammation in obesity.

Keywords: neuroinflammation, hypothalamus, chemokines, energy balance, metabolic diseases, high-fat diet, obesity, anorexia

\section{INTRODUCTION}

Energy balance is finely regulated via a bidirectional communication between the brain and the peripheral organs. One brain area is particularly important in this regulation: the hypothalamus. The hypothalamus shelters, in its different nuclei, several neuronal populations producing peptides that are either orexigenic or anorexigenic. The activity of these neuropeptidergic circuits is, among others, modulated by peripheral signals, of neural or hormonal nature, or by nutrients 
themselves (Figure 1). Thus, it would make sense that the function of these neuropeptidergic circuits would be impaired in case of feeding behavior deregulation, whether it is a loss of appetite or a food overconsumption. Numerous studies, based either on lesion, pharmacological, or genetic approaches, indeed confirmed this [for review see Ref. (1)]. Interestingly, hypothalamic inflammation has already been linked to energy balance disruptions: high-grade hypothalamic inflammation has been associated to involuntary weight loss and, on the contrary, low-grade hypothalamic inflammation has been associated to obesity $(2,3)$. Importantly, these feeding behavior deregulations represent major public health issues, especially obesity. Indeed, obesity, which keeps developing since the end of the 20th century, is often associated to potentially deadly comorbidities such as diabetes, cardiovascular diseases, liver diseases, and cancers. Yet, a loss of appetite, consecutive to some inflammatory pathologies such as cancer, can also have severe consequences, as it can impair recovery by inducing a deficit in energy.

Hence, understanding the molecular mechanisms linking hypothalamic inflammation and feeding behavior deregulations could, in the long-term, allow identifying potential therapeutic targets. As previously mentioned, we will focus in this review on hypothalamic inflammation, even though peripheral inflammation is also often associated with energy balance deregulations: in involuntary weight loss, inflammation is rather firstly systemic and a consequence of a primary pathology. In obesity, both systemic and hypothalamic inflammations have been described, and even if this is still debated, recent studies suggest that hypothalamic inflammation precedes systemic inflammation associated to the obese state (4-6).

In this context, in particular when there is systemic inflammation, it is important to understand how the periphery and the brain can communicate, especially regarding inflammatory signals. The most described brain-periphery communication pathways are the neural and the humoral pathways. The neural pathway involves primarily the vagus nerve-which expresses cytokine receptors-and the dorso-vagal complex, whereas the humoral pathway involves circulating cytokines that are overexpressed with inflammation and that can (1) bind to their receptors on the membrane of endothelial cells, (2) get to the brain at the level of the circumventricular organs and of the choroid plexus when the blood-brain barrier (BBB) is incomplete, or

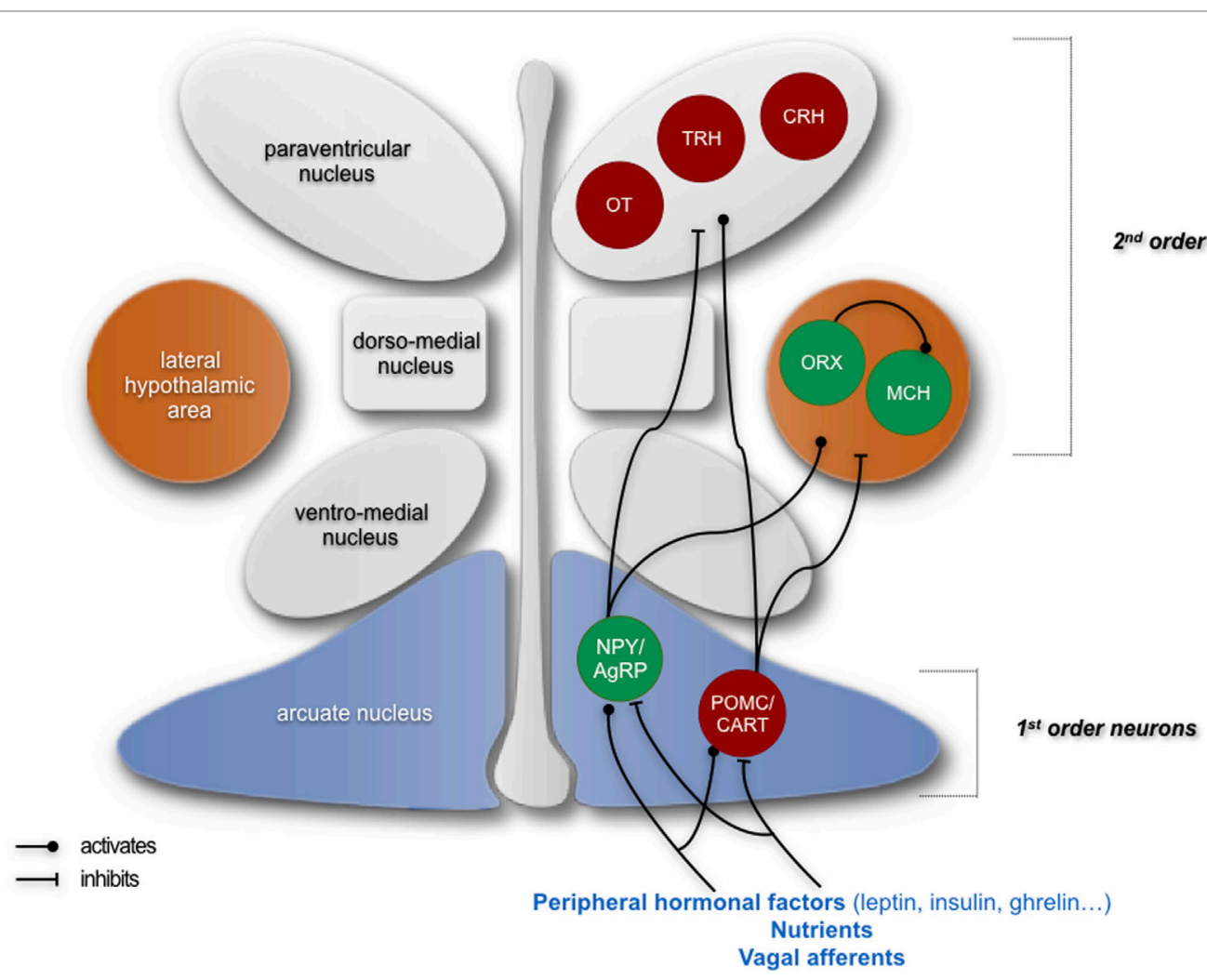

FIGURE 1 | Simplified schematics summarizing the neuropeptidergic hypothalamic networks that are involved in homeostatic regulation of feeding behavior. Signals giving indications about the energy status of an organism are emitted from the periphery and are first integrated by first-order neurons located in the arcuate nucleus, producing either orexigenic neuropeptides (NPY and AgRP) or anorexigenic peptides (POMC and CART). These neurons project to second-order neurons, such as neurons producing the anorexigenic factors oxytocin (OT), thyrotropin-releasing hormone (TRH), and corticotropin-releasing hormone $(\mathrm{CRH})$ in the paraventricular nucleus and neurons producing orexigenic peptides orexin (ORX) and melanin-concentrating hormone (MCH) in the lateral hypothalamus. The integration of peripheral signals by these neuropeptidergic systems participates in the homeostatic regulation of feeding behavior and the maintenance of a suitable weight by ensuring an appropriate food intake as well as appropriate energy intake and expenditure. In green: neurons producing orexigenic peptides; in red: neurons producing anorexigenic peptides. Adapted from Le Thuc and Rovère (7). 
(3) reach directly the brain thanks to the increased BBB permeability induced by inflammation (8). However, one must also consider the cellular pathway, which involves the infiltration of immune cells and activation of microglia in the brain parenchyma, and also the microbiota pathway, for example.

Studies that aimed to identify inflammatory mediators allowing bidirectional communication between the periphery and the brain during inflammation mainly focused on the role of peripheral cytokines. Yet, it has been suggested that in the context of disruptions of proper control of food intake and body weight, the central production of inflammatory mediators is more important than the peripheral one, or at least "necessary," in particular in the models of inflammation induced by the bacterial lipopolysaccharide (LPS), where it has been suggested that its effects do not require the signaling from peripheral cytokines (9-11).

Hence, in the context of disruptions of proper energy balance control by hypothalamic circuits, a group of pro-inflammatory mediators might be as relevant as the canonical cytokines, if not more, downstream of the latter: the chemokines. Chemokines are a subgroup of cytokines, small $(8-14 \mathrm{kDa})$ heparin-binding proteins, mainly described for their chemoattractant properties for immune cells to the affected site.

Chemokines and their receptors are suspected to be mediators of the effects of neuroinflammation, from attraction of immune cells to behavioral changes. Beyond participating in the immune response, chemokines and their receptors (the "chemokinergic system") are constitutively expressed in the brain, in a specific manner, both area wise and cell type wise. Interestingly, it is comparable to the neurotransmitters or neuropeptidergic systems $(12,13)$. Furthermore, the chemokinergic system has been demonstrated to interact with the neurotransmitter and neuropeptidergic systems $(14,15)$ and some recent studies suggest that the chemokinergic system is able to directly modulate neuronal activity (16-18). Thus, the chemokinergic system could be responsible for the behavioral changes associated to inflammation.

In this review, we discuss how inflammation, with a focus on chemokines, can participate in the deregulation of the hypothalamic control of energy balance and body weight: first, in appetite and weight loss and, second, in the establishment and/or the development of obesity.

\section{INVOLUNTARY WEIGHT LOSS AND INFLAMMATION}

Weight loss illustrates an unbalance between energy intake and energy expenditure in favor of expenditure. While both involuntary and voluntary weight losses can be caused by a decrease in food intake or an increase in energy expenditure (increase in basal metabolism, e.g., thermogenesis), only an involuntary weight loss can be explained by an uncontrolled decrease in food intake or by an increase in energy expenditure.

There are multiple possible causes for an involuntary weight loss. This weight loss can be a symptom of a severe primary disease such as cancer, where it is particularly preoccupying when it reaches or exceeds $10 \%$ in 1 year. In most cases, one can link an involuntary weight loss to psychic troubles, such as depression, that can induce a sustainable loss of appetite, thus weight loss. Excessive consumption of certain substances (e.g., drugs of abuse and alcohol) can also induce an involuntary weight loss. Yet, a weight loss is only considered "involuntary" when it is not a consequence that can be expected from a specific medical treatment of a known medical condition (19). Moreover, aging is often associated to a loss of appetite which induces, in the long-term, severe malnutrition and, obviously, weight loss. This can also be associated to sarcopenia, a geriatric syndrome characterized by loss of muscle mass and function (19). However, as previously mentioned, an involuntary weight loss can have organic causes such as gastrointestinal diseases [e.g., Crohn's disease, celiac disease (weight loss related to food malabsorption), and digestive ulcer], cardiovascular, endocrine, autoimmune, infectious diseases (e.g., HIV infection, hepatitis, and tuberculosis), neurological diseases (e.g., dementia and Parkinson's disease), or cancer $(19,20)$. In the case of cancer, weight loss is one of the first symptoms with $50 \%$ of patients with cancer reporting weight loss (21). It should be noted that the majority of the abovementioned organic causes are commonly associated with "high-grade"-in other words high-intensity-inflammation. Interestingly, even if benign and time-restricted, numerous pathological states are strongly inflammatory and associated to a reduced appetite or "anorexia." This anorexia is part of a classical defense mechanism of an organism against infection, lesions, etc., that is referred to as "sickness behavior" $(22,23)$. Sickness behavior involves various behavioral changes that primarily affect mood and energy balance, which develop parallel to infection or to another pathology (22).

Like other strategies adopted by the body to promote healing, anorexia is supposed to be temporary and beneficial. However, in the case of chronic diseases such as cancers, both appetite and weight loss can persist, leading to a further degraded state of the subject (hypoglycemic malaise, amenorrhea in women, decalcification leading to more fragile bones, teeth falling, etc.), comparable, in some aspects only linked to undernutrition, to what is observed with anorexia nervosa (24). Prolonged anorexia, irrespective of its type and its causes, is often a contributory factor to the onset of cachexia. Cachexia is a complex syndrome that cannot be fully reversed by conventional nutritional support and leads to progressive functional impairment, i.e., pathological thinness, associated with deep asthenia and organs dysfunction [decreased muscle strength, fatigue, adipose tissue (AT) dystrophy, etc.] $(25,26)$. Hence, cachexia can be defined as a complex syndrome in which inflammation leads to early satiety and anorexia, decreased fat mass, and weakness $(25,26)$. Prolonged loss of appetite may even be fatal. One can then assume that inflammation, here high-grade, could disrupt the proper functioning of the hypothalamic systems that are involved, and thus the regulation of feeding behavior. Hence, considering the serious consequences of unresolved anorexia, it is important to better understand the mechanisms linking inflammation and the cerebral centers that control energy homeostasis, because if the link between high-grade inflammation and loss of appetite and weight is established and extensively recognized, the underlying molecular mechanisms have not yet been fully resolved. 


\section{Inflammatory Pathways in the Hypothalamus and Involuntary Weight Loss}

In the hypothalamus, some studies have been able to identify some inflammatory pathways, involving different cell types, to be relevant for weight loss.

At the molecular level, as previously mentioned, the literature related to the deregulation of the control of energy balance in the anorexia-cachexia syndrome has focused on the role of pro-inflammatory cytokines, such as interleukin (IL)- $1 \beta$, IL-6, and TNF- $\alpha$. It has been shown that pro-inflammatory cytokines, whose production can be induced by infectious agents affecting peripheral organs, notably by LPS - the most commonly used model for modeling disease behavior and anorexia associated with inflammation (27) - participate in the induction of sickness behavior.

Some studies deciphering the kinetic aspects of the effect of central or peripheral cytokine injection suggest that proinflammatory mediators exert their effect primarily at the central level versus periphery $(28,29)$. Numerous studies have focused on IL- $1 \beta$ and have shown that its intracerebroventricular (ICV) injection induces profound behavioral changes in rodents (30). Furthermore, the central role of cytokine signaling at the central level has been confirmed, for example, by the fact that the central injection of the IL- $1 \beta$ receptor antagonist prevents the effects induced by the peripheral injection of this cytokine $(31,32)$. In addition, some studies suggest that inflammatory inducers such as LPS are not capable of directly inducing sickness behavior and require downstream actors such as cytokines. Indeed, for example, unlike the central injection of LPS, central injection of IL-1 is able to induce sickness behavior in mice whose LPS toll-like receptor (TLR) 4 is nonfunctional (33).

As mentioned earlier, cytokines, involved in the induction and regulation of sickness behavior at the central level, can be released into the circulation by the immune cells (8) or directly produced by neurons and glial cells in the central nervous system (CNS) (34-39). In the context of systemic diseases, the central effects of these cytokines appear to be independent of the place of their secretion. As previously mentioned, when produced in the periphery, cytokines have the following two main pathways to act on the brain: a neural pathway and a humoral pathway. Most cytokines act in a paracrine manner at the site of infection, suggesting that neural afferents may be the target of pro-inflammatory cytokines. Interestingly, the perineural sheath of the vagus nerve contains immune cells that are capable of producing IL-1, in particular in response to LPS (40). Furthermore, the sensory neurons of the vagus nerve express IL-1 receptors and it has been shown that this cytokine stimulates the sensory activity of the vagus nerve (40). Vagotomy experiments have demonstrated the importance of the vagus nerve in the transmission of information from the periphery to the brain: for example, after injection of LPS or IL-1 at the periphery, vagal afferents are involved in the induction of the sickness behavior and in the neural activation of the brainstem, the hypothalamus, and the limbic structures (40).
Chronic administration of cytokines can reproduce the characteristics of anorexia-cachexia syndrome $(38,41-44)$, while blocking the signaling of one of them, such as TNF, by the use of neutralizing antibodies, inhibits its development $(42,45,46)$. Similarly, administration of an IL-1 receptor antagonist prevents anorexia in cancer animal models (47). Some studies have suggested that endogenous brain IL-1 is a mediator of LPS-induced anorexia by acting on the expression of cytokines in the hypothalamus (9). In addition, it appears that IL-1 $\beta$ can act on ARC POMC neurons (48) and that TNF- $\alpha$ indirectly increases energy expenditure via $\beta 3$ adrenergic signaling in the brown AT (thermogenesis) (49). By different approaches, it has been shown that interfering with mediators of inflammation coincides with a reduction in hypothalamic inflammation and prevents weight loss in animal models of anorexia: for example, the inhibition of the "adenosine monophosphate protein kinase" in the hypothalamus reduces hypothalamic inflammation, which is accompanied by an increase in food intake in the case of cancer-associated anorexia, allowing better overall survival (50). Interestingly, in the context of cancer-associated cachexia, the administration of ghrelin, an appetite-stimulating hormone, increases food intake and is accompanied by a decrease in IL-1 $\beta$ (51).

Focusing on the LPS-induced anorexia model, it is interesting to underline that some studies suggest that this loss of appetite is independent from the vagal afferents and that it only depends on central inflammatory mechanisms, where the central effects of peripheral LPS could be, among others, mediated by some cytokines and/or via receptors for LPS expressed by some brain cells $(11,52)$. Indeed, microglia expresses TLR4, through which LPS has been shown to exert some of its effects (53-56). Furthermore, Hines and colleagues have shown that disrupting TLR4 signaling prevents microglial activation, inhibits the production of cytokines, and prevents the development of the sickness behavior that are induced by peripheral LPS (57). In contrast, a recent study by Reis et al. has shown that if microglia and TLR4 are necessary for LPS to acutely induce inhibitory effects on orexigenic agouti-related peptide (AgRP)/neuropeptide Y (NPY) neurons, conversely, LPS can actually acutely increase the firing activity of anorexigenic pro-opiomelanocortin (POMC) neurons in a microglia/TLR4-independent manner (58). In addition, the same study presents results which further supports that mediators of inflammation such as microglia and TLR4 can, at least acutely, affect basal food intake and hormonal-dependent modulation of feeding behavior. Indeed, the inhibition of microglia alone, via ICV injection of minocycline, leads to an increase in food intake, comparable to the one induced by ICV ghrelin (58). Interestingly, the co-injection of ghrelin and minocycline does not synergistically increase food intake. This implies that the inhibition of microglia itself, as it increases food intake, interferes or prevents ghrelin's orexigenic effects (58).

Changes in gene expression of hypothalamic anorexigenic and orexigenic neuropeptides were assessed in mice or rats that received LPS IP injections (59-61). Generally, peripheral LPS appears, initially, to reduce the expression of the orexigenic peptides and, on the contrary, to increase that of the anorexigenic peptides. In later stages, the expression of orexigenic peptides 
increases again, probably to promote food intake and compensate for weight loss.

Some authors have used other models to study to understand links between inflammation in the brain and the induction of sickness behavior.

For example, Jang and colleagues sought to determine the mechanisms behind anorexia and weight loss associated with illness via administration, in mice, of either bacterial or viral products: LPS and human immunodeficiency virus-1 transactivator protein (Tat), respectively (62). They found in both cases that pro-inflammatory cytokines such as IL- $\beta$, IL-6, and TNF- $\alpha$ were upregulated in the hypothalamus. Furthermore, AtT-20 and SH-SY5Y cells treated with either Tat or LPS exhibit increased POMC transcriptional activity. In addition, the injection of Tat or LPS in the hypothalamus of mice induces in both cases a decrease in food intake and in body weight. They identified POMC as a potential mediator of illness-induced anorexia and as a possible downstream target of NF- $\mathrm{KB}$. Indeed, they showed through different approaches that the NF- $\kappa \mathrm{B}$ pathway in the melanocortin system plays an important role in illness-induced anorexia and body weight loss: both administration of AgRP, an endogenous melanocortin antagonist and the inhibition of the $\mathrm{NF}-\kappa \mathrm{B}$ pathway specifically in the POMC neurons $\left(\operatorname{Ikk} \beta^{\Delta \mathrm{Pomc}}\right.$ mice), significantly blunted the effects of Tat and LPS on food intake and body weight. Interestingly, the authors also present results suggesting that leptin-induced anorexia is also dependent on the NF- $\kappa B$ pathway (62).

Another study has shown that a pathway involving TLR2 participates in the induction of sickness behavior through a microglia-POMC neurons axis (63). In this publication, the authors show, by ICV injection of Pam3CSK4, a specific synthetic TLR2 agonist that TLR2 central signaling is able to trigger sickness behavior through activation of microglial cells, which express TLR2, and via the NF- $\mathrm{KB}$ and COX pathways. The authors also show that activation of central TLR2 is able to modify the synaptic architecture in the ARC, especially at the level of the POMC neurons: it reduces the rate of GABAergic contacts on POMC neurons, whereas it increases the vesicular glutamate transporter 2 (vGLUT2) contacts on POMC soma, translating an increased excitatory state, in correlation with an increased microglial occupancy.

In addition, Murray et al. used the peripheral administration of the viral mimetic poly I:C to induce type-I interferons (IFN-I) overexpression in the brain. Using IFN-I receptor 1 (IFNAR1)deficient mice, the results of the authors present suggest that IFN-I are involved in the induction of sickness behavior, including anorexia, whereas IL-6 participates in sickness behavior but not in anorexia (64).

Furthermore, a local increase in serotonin levels in the hypothalamus has already been linked to anorexia and cachexia (65-67) and a recent study showed that inflammation induced by peripheral treatment by either IL- 6 and/or TNF- $\alpha$ is associated with an impairment in local serotonin turnover in the hypothalamus, a decrease in NPY and AgRP gene expressions, and a decrease in food intake in comparison to control conditions (68). Authors were able to identify upstream inflammatory regulators including interferon gamma (IFN- $\gamma$ ), transforming growth factor beta (TGF- $\beta$ ), IL- 6 , and IKBKG, an enzyme crucial for the activation of the NF- $\kappa B$ pathway. This study thus suggests that peripheral inflammation reaches the hypothalamus where it impairs serotonin turnover, which is associated to a decrease in food intake.

Taken together, numerous studies support the hypothesis that inflammation at the hypothalamic level is able to disrupt the proper function of neuropeptidergic circuits of the hypothalamus and thus to induce an involuntary weight loss.

However, mediators linking inflammation and its consequences at the level of central systems regulating energy homeostasis, and ultimately on weight, have not been determined with certainty, and one may note that the nature of the mediators responsible for the central effects of IL-1 $\beta$ has been especially poorly described. Thus, chemokines can represent interesting candidates to study further understanding of the underlying mechanisms.

\section{Chemokines in the Modulation of Hypothalamic Neuropeptidergic Circuits in Inflammation- Associated Involuntary Weight Loss}

So far, very few studies have sought to determine if chemokines have a role in the induction of involuntary weight loss associated with inflammation by impairing the homeostatic regulation of energy balance by hypothalamic neuropeptidergic circuits.

A study published in 1994 by Plata-Salamán and Borkoski aimed to investigate how chemokines could act on the regulation of feeding. Indeed, as previously mentioned, chemokines are produced in multiple types of cells as a response to pathological conditions such as infection, inflammation, injury, and trauma. Among the stimuli that can induce the release of these chemokines, we can list LPS, and also the IL- $1 \beta$, TNF- $\alpha$, and IFN, which have been associated to food intake suppression by direct action on the CNS. Thus, the authors aimed to determine if chemokines could be involved, as downstream mediators, in the decrease in food intake induced by inflammatory signals such as LPS. In order to do so, they used, in rats, ICV microinfusion of different chemokines from two different subfamilies: CXC and CC, also known as the $\alpha$ and $\beta$ subfamilies. This way, they tested the effect of CXC-motif chemokine ligand (CXCL)-1, 4, 7, 8, 10 and CC-motif chemokine ligand (CCL)-2-4, 5. Even though it is at a lesser extent than the cytokine IL-1 $\beta$, their results indeed identify certain chemokines as capable of acutely decreasing food intake: CXCL4, CXCL8, CXCL10, CCL2, and CCL5. Interestingly, in their model, these chemokines would affect feeding behavior at different time scales: if they all reduced food intake in the $2 \mathrm{~h}$ following injection, only CXCL8, CXCL4, and CCL2 were able to reduce food intake over the whole dark phase and only CXCL8 and CXCL4 were able to decrease the total daily food intake (69). This study is particularly important as it sets chemokines as contributors, in the brain, to the effects of infection/inflammation on feeding behavior. Nevertheless, no mechanistic insights were then provided.

As previously acknowledged, very few studies aimed at better characterizing how chemokines could modulate feeding behavior after this study by Plata-Salamán and Borkoski.

Yet, in a recent study from our laboratory (70), we sought to identify and characterize chemokines that could possibly 
deregulate the hypothalamic circuits to alter food intake and energy balance in anorexia and weight loss. We thus assessed the gene expression of several pro-inflammatory mediators in the hypothalamus of mice that had received an acute ICV injection of LPS. After confirmation of LPS-induced inflammation in our mice by observing the overexpression of several pro-inflammatory mediators, we then identified ligands of the chemokine receptors CCR (CC-motif chemokine receptor)-2 and 5 as the most overexpressed. Among them, CCL2 (also known as monocyte chemoattractant protein 1) caught our attention as it has been described as particularly important in the context of LPS-induced neuroinflammation and suggested to be able to reduce food intake $(69,71-73)$. Thus, we focused on the central signaling of CCL2 and its receptor CCR 2 and could demonstrate that it is mandatory for both metabolic and behavioral changes induced by LPS (70). Indeed, inhibiting CCR2 signaling by combined ICV injection of a specific antagonist of CCR2, INCB3344, together with LPS, prevents the weight loss that is induced by ICV injection of LPS alone. Similarly, the weight loss induced by ICV injection of LPS is reduced in mice deficient for CCR2 in comparison to control animals. Experiments in metabolic cages demonstrate that central injection of LPS decreases both food intake and locomotor activity, whereas it increases fat oxidation and induces a shift in used energy substrate in favor of lipids versus carbohydrates. These two last points probably illustrate an increased use of the energy stocked in the AT as lipids. Interestingly, these LPS effects highlighted by the metabolic cages experiments were also reduced when interfering with central CCR2 signaling by co-ICV injection of LPS and INCB3344.

We then identified the neurons, which produce melaninconcentrating hormone $(\mathrm{MCH})$, a peptide known to elicit food intake and to decrease energy consumption, as targets for CCL2 (74). After ICV injection of LPS, we observed a sustained decrease in gene expression and protein levels of $\mathrm{MCH}$, which is blunted/prevented by pharmacological (using INCB3344) or genetic inhibition of CCL2 signaling. Interestingly, we found that, similar to LPS, ICV injection of CCL2 promotes neuroinflammation, together with a decrease in both $\mathrm{MCH}$ expression and body weight. Immunostaining experiments showed that $70 \%$ of the $\mathrm{MCH}$ neurons of the lateral hypothalamus (LHA) express CCL2 receptor. These neurons responded to CCL2 by decreasing both electrical activity and $\mathrm{MCH}$ release. Thus, it seems that the inhibition of the MCH system by LPS depends primarily of the central signaling of CCR2. Moreover, in experiments of perifusion of hypothalamic explants treated with $\mathrm{KCl}$ and CCL2, $\mathrm{MCH}$ secretion is totally inhibited, while co-application of $\mathrm{KCl}$ and INCB3344 only, leads to enhanced secretion of $\mathrm{MCH}$. This suggests that endogenous CCL2 could participate, in normal conditions, in modulating $\mathrm{MCH}$ system and thus energy balance regulation.

Thus, it appears that the central CCL2/CCR2 axis is able to directly act on neurons producing the orexigenic peptide $\mathrm{MCH}$ by reducing their activity and both the expression and secretion of the peptide, leading to a reduced food intake and to an increased use of energy stores. Hence, the central CCL2/CCR2 axis, by acting through $\mathrm{MCH}$ neurons, appears as a major actor in appetite and weight loss associated with LPS-induced inflammation
(Figures 2 and 3). This study was the first to demonstrate that a chemokine can play a role, at the central level, in energy balance deregulation, by acting directly on neuropeptidergic systems in the hypothalamus.

\section{OBESITY AND INFLAMMATION}

As previously mentioned, interestingly, inflammation is also a characteristic for an opposite disorder of the energy balance disorder of the regulation of food intake and body weight: obesity. Yet, different from the inflammation associated to involuntary weight loss, this inflammation is of low intensity, also referred to as a "low-grade" inflammation (79). Obesity is characterized by an excessive fat mass distributed throughout the body that can be harmful to health [source: World Health Organization

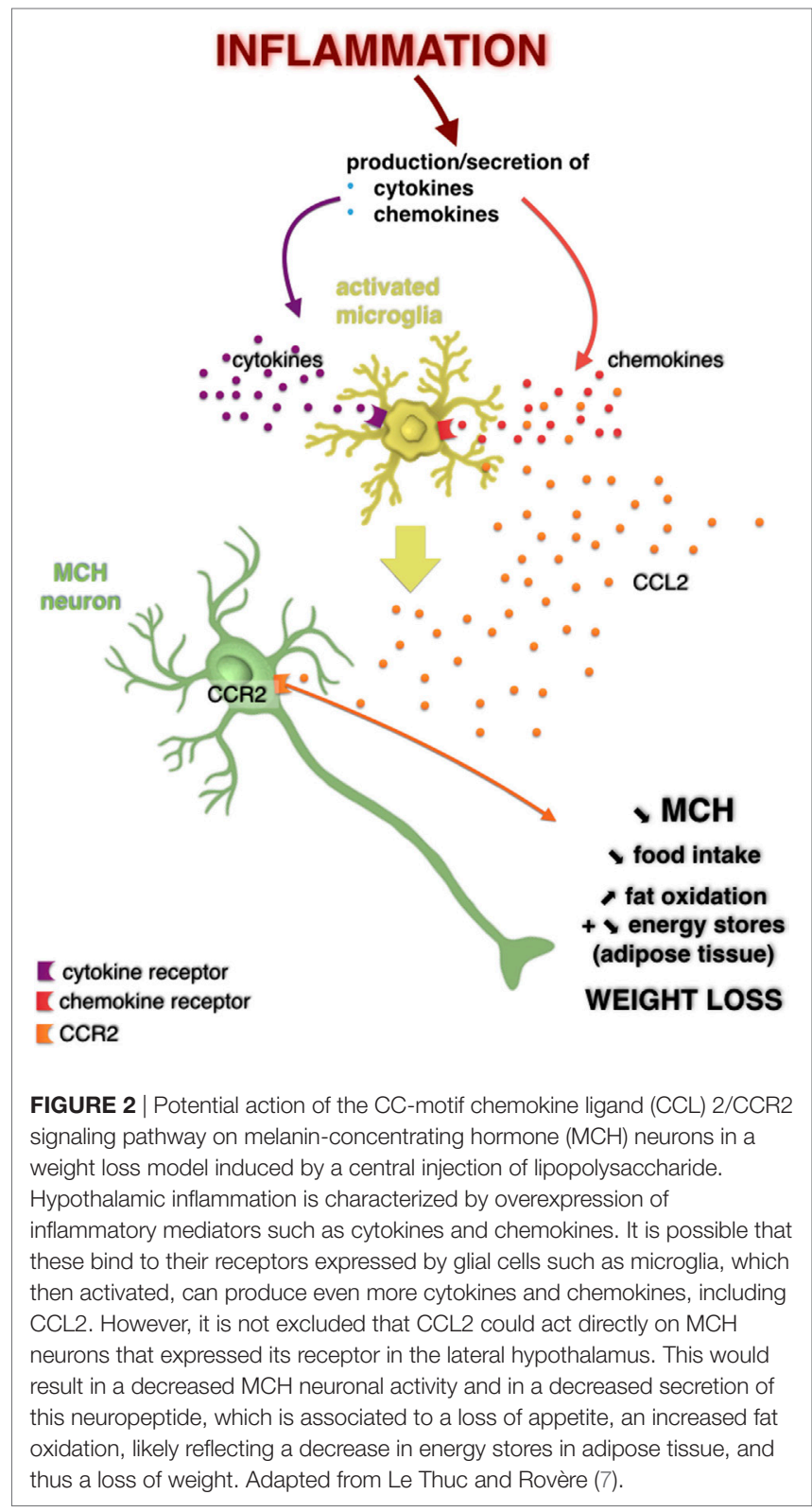




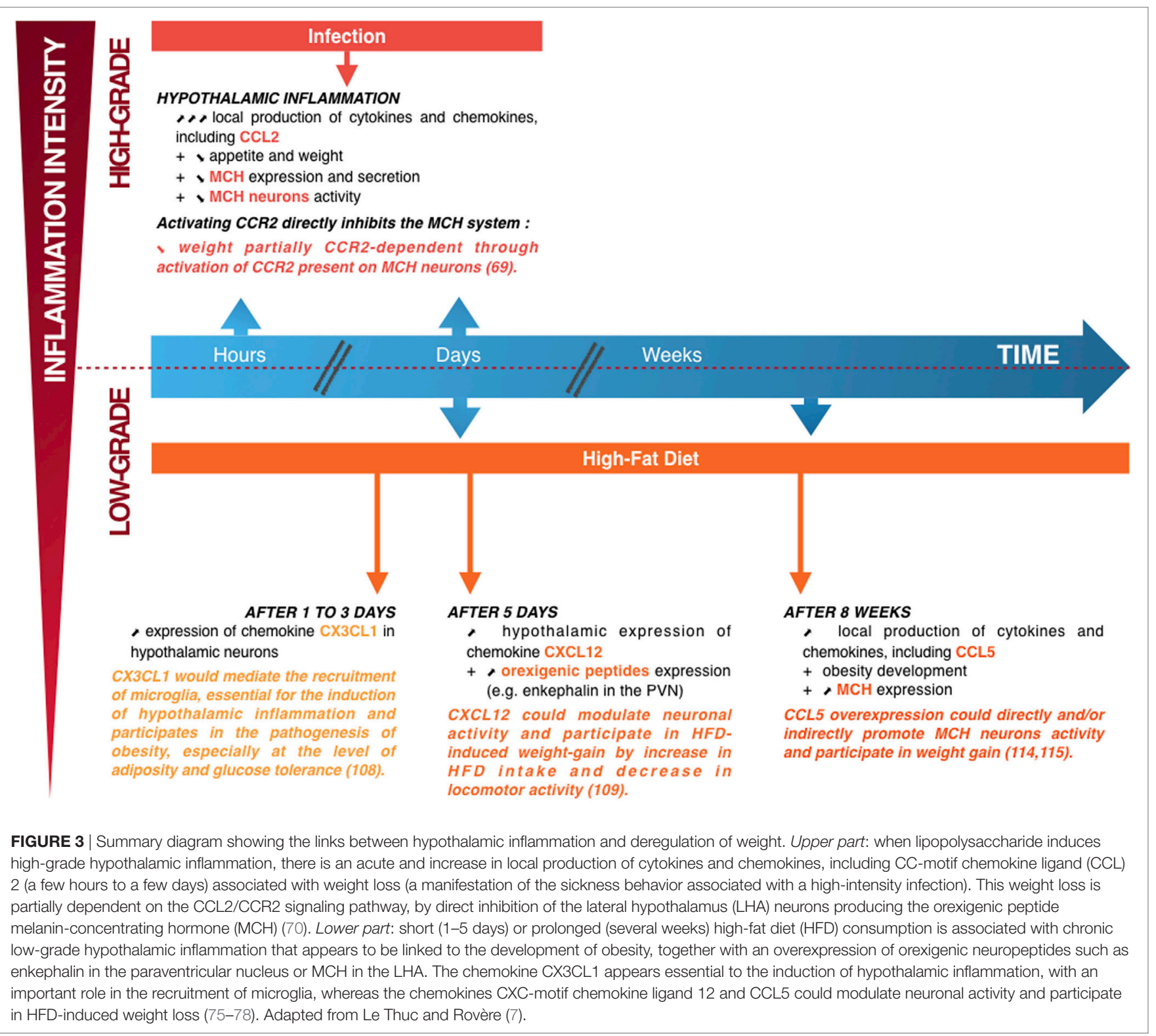

(WHO)]. One is considered obese if one's body mass index is greater than or equal to $30(80,81)$. Worldwide, close to $13 \%$ of the population were obese in 2014 and the prevalence of obesity nearly doubled between 1980 and 2014 (source: WHO). Obesity is a concern as it represents a risk factor for chronic diseases such as cardiovascular diseases (hypertension, heart disease, and stroke), diabetes, hepatic steatosis, respiratory diseases, musculoskeletal disorders (osteoarthritis, etc.), certain cancers (endometrium, breast, colorectal, etc.), and neurodegenerative disorders (79-81). Furthermore, childhood obesity, which is progressing in an alarming manner, can promote respiratory difficulties, high blood pressure, the emergence of markers of cardiovascular disease, fractures, insulin resistance, and psychological problems. All these aspects in turn increase the risk of adult obesity, premature death, and disability in adulthood (source: WHO).
While the development of obesity may be explained by some genetic aspects or be consecutive to a primary disease and/or its treatment (hormonal and/or psychological factors, drugs, etc.), its most common cause is a change in the population's life-style. This encompasses an increase in sedentariness and hypercaloric diets overconsumption, where the excess in calories intake most often comes from lipids and also carbohydrates $(80,81)$. As obesity represents a major and growing public health issue, it becomes important to identify and understand its causes and mechanisms. Therefore, understanding the role played by inflammation, both peripheral and central, in the establishment and/ or development of obesity and its comorbidities might allow to identify new potential targets in the fight against obesity.

The inflammation associated to obesity exhibits several specificities: first, as mentioned previously, it is low grade and chronic. So far, it has been mostly described in peripheral tissues 
(AT, liver, pancreas, etc.). Nevertheless, more recently, it has been shown to also occur in the CNS: a hypercaloric challenge, especially a high-fat diet (HFD), even on the short term, can induce an inflammation in the hypothalamus that is sustained in models of nutritional obesity (82).

\section{Obesity and Peripheral Inflammation}

Studies have associated inflammation and obesity for a long time (79). Yet this inflammation is not "typical," as it cannot be associated to the cardinal signs of redness, swelling, heat, and pain. Thus, the inflammation associated to obesity is of different nature. First, it is aseptic: it is caused by the overconsumption of specific nutrients (lipids and carbohydrates); thus, the trigger of this inflammation can be considered to be of metabolic nature. Interestingly, not only the trigger of this inflammation is metabolic, but this inflammation first targets the cells that specialized in metabolism: e.g., adipocytes, hepatocytes, pancreatic $\beta$-cells, and myocytes (but also the neurons of the peptidergic systems involved in the regulation of feeding behavior, as detailed further). Hence, this inflammation is often referred to as "metabolic inflammation" or "metainflammation" (79).

The characteristics of the inflammation associated with obesity, in periphery at least, are: (i) being of metabolic nature-it is induced by nutrients and is orchestrated by "metabolic" cells; (ii) being low grade, with moderate and localized overexpression of pro-inflammatory mediators; (iii) creating an impaired milieu where the tissue "composition" in terms of immune cells favors an inflammatory environment in the tissues; and (iv) being sustained in time, without any apparent resolution (79). Furthermore, peripheral metabolic inflammation associated with obesity is deleterious at many levels and, as a consequence of poor eating habits favoring the obese phenotype, inflammation itself promotes tissue dysfunctions, which also contribute to development of obesity, including resistance to insulin and leptin.

\section{Obesity and Hypothalamic Inflammation}

In the context of nutritional obesity, inflammatory pathways are not only activated in peripheral tissues but also activated in central areas involved in the control of energy metabolism, especially in the hypothalamus. Several questions then deserve to be asked and answered such as "What are the signals that induce this inflammation?" and "Is inflammation a cause or a consequence of obesity?"

The relationship between nutritional obesity and hypothalamic inflammation was first described by De Souza and his collaborators (83). The authors demonstrated in rats that a 4-month period of HFD feeding activates inflammatory pathways in the mediobasal hypothalamus (MBH), such as JNK and NF- $\kappa B$, leading to the production of canonical pro-inflammatory cytokines such as IL- $1 \beta$, TNF- $\alpha$, and IL- 6 and to deficiencies in insulin and leptin signaling. These observations on hypothalamic inflammation associated to nutritional obesity were confirmed in rats, obese mice, and non-human primates (82, 84-92). Interestingly, some studies have shown that the inflammation induced by the consumption of HFD, likely a response to overnutrition, develops much faster in the hypothalamus than in the peripheral tissues. Indeed, inflammation in the AT, for example, is only observable after several weeks or even months, whereas in the hypothalamus, the consumption of a HFD during a much more restricted period of 24-72 h is enough to induce overexpression of proinflammatory cytokines and gliosis-which corresponds to an activation and proliferation of glial cells such as microglia and astrocytes, an inflammation hallmark in the brain (82).

Thus, it appears that the inflammation induced by the excess of nutrients in the hypothalamus precedes the establishment of obesity, as well as peripheral inflammation and metabolic disturbances. It is worth mentioning that the gliosis induced by the consumption of a HFD for a short-period of time (2-3 weeks) is actually reversible, whereas it reappears after longer periods of HFD consumption (8 months) (82). This suggests that the initial short-term gliosis is rather a protective mechanism induced to protect against the "injury" induced by the overload of fat, which is in line with the known roles of these cells, and that with time, the consumption of HFD triggers a durable gliosis and inflammation that would then play a major role in the development of the pathophysiology induced by overnutrition. For example, a study by Dalvi et al. further supports that acute gliosis associated with a moderate period of HFD feeding would actually be protective: as long as the inflammation is restricted to glial cells, the organism seems to attempt to limit brain injury by overexpressing in parallel some protective factors such as the heat shock protein 70 and the ciliary neurotrophic factor. After a longer period of HFD feeding, overexpression of inflammatory mediators within the neurons suggests an exhaustion of neuroprotective mechanism in the hypothalamus, leading to a deregulation of the expression of certain neuropeptides that will favor a positive energy balance (93).

What is the signal that triggers hypothalamic inflammation? It has been suggested that it is the excess of nutrients, which are major physiological regulators of hypothalamic neural networks, that induces the establishment of inflammation at the level of the hypothalamus. Some studies attribute the triggering of hypothalamic inflammation to, more especially, saturated fatty acids (SFA), especially long-chain SFA, due to their accumulation in the hypothalamus when consuming HFD, which could, among others, induce inflammatory signaling by activating the TLR4 pathway. It is interesting to note that other fatty acids, such as long-chain polyunsaturated fatty acids, appear, conversely to long-chain SFA, to be beneficial, especially in the diet-induced obesity (DIO) context, as they have anti-inflammatory properties (94-97). In contrast, not only nutrients but also hormones seem to play a role in the regulation of glial cells function. Indeed, as illustrated by a study by Gao et al., showing that monogenic obese mice with deficient leptin signaling [ob/ob (leptin deficient) and $d b / d b$ (leptin receptor mutation)] exhibit less microglial activation than wild-type controls both on chow and on HFD (98). The authors further demonstrated that the lack of leptin signaling affects also the microglial function in the hypothalamus as the expression of several inflammatory mediators is reduced (98). This indicates that the signaling of leptin, already described as a pro-inflammatory adipokine (99), could affect microglial activation. Other mechanisms have been proposed as mediators of the hypothalamic inflammation associated with overnutrition such as the endoplasmic reticulum stress $(86,100,101)$. Similarly, 
oxidative stress could be an initiating factor and participate in the maintenance of the hypothalamic inflammation induced by nutrition. Indeed, at the periphery, oxidative stress, along with the production of reactive oxygen species (ROS), has been shown to precede severe metabolic disturbances and insulin resistance (102). Yet, the brain alone uses a large amount of the oxygen and calories consumed by the body, making it particularly vulnerable to excessive ROS production and oxidative stress. Indeed, mitochondria naturally produce ROS in physiological conditions, especially during the oxidation of nutrients such as glucose or fatty acids (103), and it has been shown that an excessive production of ROS in the hypothalamus occurs in the obese rat. This impairs not only the local detection of glucose but also the associated physiological response, such as peripheral insulin secretion (104). Autophagy is another possible pathway. It is a cellular process allowing the elimination of damaged cytoplasmic elements and organelles in order to maintain internal homeostasis and structural integrity and also plays a key role in cellular responses to metabolic stress. Under conditions of overnutrition, endoplasmic reticulum stress and oxidative stress can induce autophagy (105, 106). Impairing the pathways of autophagy can increase food intake and weight, in association with overactivation of the IKK $\beta / N F-\kappa B$ pathway in the hypothalamus, illustrating the connection between autophagic and inflammatory pathways in the hypothalamus.

Over the recent years, the importance of the role played in hypothalamic inflammation in the onset of metabolic disorders in obesity was indeed underlined and the potential of counteracting inflammation in the hypothalamus as a strategy in the fight against obesity was highlighted.

For example, a recent study by Douglass and colleagues demonstrates that astrocytes in the MBH of HFD-fed mice mediate hypothalamic inflammation together with DIO via their own inflammatory signaling (107). Indeed, the authors showed that the inducible and specific deletion of IKK $\beta$ in astrocytes, which should blunt astrocytic inflammatory capacity, reduces the mice susceptibility to DIO (reduced weight gain and fat mass associated with a decrease in food intake and an increase in energy expenditure), improves glucose tolerance and insulin sensitivity (according to glucose and insulin tolerance tests), and finally, reduces HFD-induced astrocytosis in the $\mathrm{MBH}$.

Furthermore, it has been shown that subcutaneous application of liraglutide or canagliflozin (an inhibitor of the sodium-glucose cotransporter 2) in obese and insulin-resistant rodents is able to disrupt the activation of microglial cells in the hypothalamus, which is associated with an improvement of insulin and glucose homeostasis. In addition, when the ICV injection of IL-4 in HFD-fed rats increases further HFD-induced inflammation in the hypothalamus and causes excessive weight gain, the ICV injection of an IKK $\beta / \mathrm{NF}-\kappa \mathrm{B}$ blocker allows, on the contrary, to prevent hypothalamic inflammation, which is associated with both a decrease in body weight and fat mass and improvements in glucose metabolism and general energy homeostasis in DIO animals $(86,108-111)$.

Another study by André et al. shows that overnutrition will induce, in addition to an increase in body weight and in adiposity, an increase in the number of microglial cells in the ARC. The authors show the inhibition of microglia expansion in the ARC, achieved by the central delivery of an antimitotic drug, allows to limit food intake and the increase in body weight and in adiposity and also to restore leptin sensitivity. This is associated with a "predictable" inhibition of the upregulation of inflammatory pathways in the ARC that is normally associated with overnutrition, but also in periphery (112).

Taken together, studies studying the hypothalamic inflammation associated with obesity support that this inflammation plays a key role in the metabolic dysfunctions associated with obesity and represents a very interesting target.

Research aiming to understand how the central regulation of energy balance is altered in the context of overnutrition has mainly focused on neurons so far. Yet, as previously mentioned, since hypothalamic inflammation, especially its gliosis feature, has been associated to overnutrition, a strong interest in the role of glial cells (mainly microglia and astrocytes) emerged more recently. Interestingly, these glial cells, once activated, are capable of overproducing, locally, pro-inflammatory mediators such as cytokines and chemokines that can, in turn, affect the neuropeptidergic systems of the hypothalamus, potentially participating in the onset of obesity.

Interestingly, chemokines and their receptors have been demonstrated to be expressed by glial cells, and also by neurons. Especially, chemokine receptors appear to be more expressed by neurons than cytokine receptors in some nuclei of the hypothalamus, allowing to ask the following question: "Could not chemokines act as one of the latest inflammatory mediator that would link inflammation to the disruption of the proper functioning of the neuropeptidergic systems involved in the regulation of the energy balance to promote weight gain and thus the development of obesity?"

\section{Chemokines in the Modulation of Hypothalamic Neuropeptidergic Circuits in DIO}

As it was the case in the context of hypothalamic inflammation and involuntary weight loss, only few studies have aimed to determine and understand if and how chemokines are able to alter the function of hypothalamic neuropeptidergic circuits and thus participate in the development and/or the maintenance of obesity.

A study by Morari and colleagues has identified fractalkine (or CX3CL1) as involved in the early activation of hypothalamic inflammation in a murine model of DIO, likely through recruitment of microglial cells which express CX3CR1, the receptor for CX3CL1 (75). In this study, the authors show that, early after HFD introduction to the mice (1-3 days), CX3CL1 is induced in hypothalamic neurons of obesity-prone mice, unlike what was observed in obesity-resistant mice. Interestingly, the inhibition of CX3CL1 in the MBH by an approach of small interfering RNA allows a reduction in inflammation, glucose intolerance, and diet-induced adiposity (no significant difference in body weight was observed though). It suggests that CX3CL1, mediating early recruitment of microglia induced by HFD and thus participating in the induction of hypothalamic inflammatory response, participates in the pathogenesis of obesity as it impairs glucose tolerance and adiposity (Figure 3). 
In addition, one recent study highlights the role of the axis CXCL12/CXC-motif chemokine receptor 4 (CXCR4) in the paraventricular nucleus (PVN) of the hypothalamus in mediating both neuronal and behavioral effects of the consumption of a HFD in rats (76). In more details, the authors show that a 5-day consumption of a HFD induces an overexpression of CXCL12 and its receptors CXCR4 and CXCR7 both in the PVN and in the perifornical lateral hypothalamus (PFLH). The authors also show that HFD is able to induce an overexpression of orexigenic neuropeptides enkephalin and galanin in the PVN and orexin (ORX) and $\mathrm{MCH}$ in the PFLH. Moreover, HFD is associated with an increase in the number of CXCR4 ${ }^{+}$cells in the PVN. Conversely, in the arcuate nucleus, the levels of CXCL12 and CXCR4 were too low to be detected. The ICV injection of CXCL12, next to the hypothalamus, is able to recapitulate the effects of HFD consumption: (1) it reduces novelty-induced locomotor activity, as a 5-day HFD feeding period does; (2) it is associated to an increase in gene expression of enkephalin in the PVN; and (3) it induces an acute increase in calorie intake (by overconsumption of the HFD only and no consumption of chow diet, as rats had access to both diets). This last point interestingly suggests that CXCL12 could participate in the control ingestive behavior, especially since some different studies also previously demonstrated that CXCL12 could affect other systems such as the MCH and vasopressin in the hypothalamus or dopamine in the substantia nigra $(18,113,114)$. Taken together, these results suggest that CXCL12 could modulate the activity of orexigenic peptide-producing neurons, especially the encephalin neurons in the PVN. This would favor HFD intake and decrease locomotor activity and, thus, participate in HFD-induced weight gain (Figure 3).

The chemokine CCL5, also known as RANTES for Regulated on Activation, Normal T Cell Expressed and Secreted, has already been linked to obesity-associated inflammation in periphery. Indeed, obesity is associated with an increase in CCL5 secretion and gene expression in AT in obese human and mice. There, CCL5 is suspected to mediate the increase in the local accumulation of T cells and macrophages, which is involved in the complex genesis of chronic inflammation $(115,116)$. In addition, our joint study with Dr. Karine Clément's team proposed CCL5 as biomarker of weight evolution in patients undergoing bariatric bypass surgery Roux-en-Y as its levels were nearly eightfold higher in the serum of obese patients than in the one of control patients. CCL5 seems to be the only chemokine of which serum levels appear to be correlated with caloric intake in patients undergoing bariatric bypass surgery Roux-en-Y: they rapidly decrease after surgery, as caloric intake decreases and, later on, when patient's caloric intake and body weight start increasing again, they also increase again (77). This justified further interest in the potential role of CCL5 as a modulator of the activity of hypothalamic neurons regulating food intake and which could possibly promote the establishment and/or development of obesity. Thus, our group characterized its expression profile, both at the peripheral and hypothalamic levels in a model of nutritional obesity in mice. In this model, we found both peripheral and central inflammations, as evidenced by the overexpression of canonical pro-inflammatory mediators in the serum and hypothalamus.
CCL5 was also found to be overexpressed in the periphery and in the hypothalamus of obese animals (78). An ICV injection of CCL5 on the expression of orexigenic peptides $\mathrm{MCH}$ and ORX seems able to increase the expression of both ORX and $\mathrm{MCH}$, transiently for ORX and in a more stable and persistent manner for $\mathrm{MCH}$. Furthermore, it would appear that CCL5 is capable of depolarizing $\mathrm{MCH}$ neurons, thus facilitating their activation (78). These results indeed suggest that CCL5 is acutely able to modify the activity of the hypothalamic orexigenic MCH system. Taken together, these results suggest that the overexpression of CCL5 would promote the overactivation of hypothalamic $\mathrm{MCH}$ neurons and thus participate in weight gain (Figure 3). Whether CCL5 is a cause or a consequence of obesity, or if it could effectively disrupt the proper function of the neuropeptidergic circuits of the hypothalamus, which regulate energy balance and promote the establishment of obesity, is nevertheless still matter of investigation.

\section{CONCLUSION}

As of today, a substantial amount of publications supports that hypothalamic inflammation mediates disruptions in the hypothalamic control of energy homeostasis, especially regarding body weight regulation. If some pathways and cellular actors have been identified, mechanisms are still ill-described and poorly understood.

Chemokines have long been considered as essential mediators of the inflammatory response, but more particularly because of their ability to activate and attract immune cells to the affected site. However, at the central level, the literature has also attributed to chemokines and their receptors, beyond their role in the attraction of leukocytes in the cerebral parenchyma, important roles in neuronal survival as in neurotoxicity, cerebral development, communication between immune and glial cells, and also communication between neurons and glial cells (since all these cell types have been shown to be able to express the actors of the chemokinergic system) and also in neuromodulation $(15,18)$.

Several studies now support the hypothesis that chemokines are actually able to modulate the activity of certain neurons. We and others were able to demonstrate that their overexpression is able to deregulate the neuropeptidergic systems of the hypothalamus, which participate in the regulation of the energy balance and participate in the development of deregulations of the latter, whether it is an excessive weight loss or gain (Figure 3). Moreover, this does not, in any way, exclude that, under physiological conditions, the chemokines are actors of this regulation. These studies on chemokine central signaling now identify chemokines as novel potential therapeutic targets against deregulations of the energy balance.

\section{ETHICS STATEMENT}

The protocols were carried out in accordance with French standard ethical guidelines for laboratory animals and with approval of the Animal Care Committee (Nice-French Riviera, project agreements no. 04042.01 and 04464.01). 


\section{AUTHOR CONTRIBUTIONS}

OLT conceived and wrote the manuscript. OLT also made the figures. OLT and KS realized the bibliography researches. CC, JLN, NB, and CR critically appraised and revised the manuscript and figures. All authors listed made substantial, direct, and intellectual contribution to the work and gave permission for this manuscript to be published.

\section{REFERENCES}

1. Waterson MJ, Horvath TL. Neuronal regulation of energy homeostasis: beyond the hypothalamus and feeding. Cell Metab (2015) 22:962-70. doi:10.1016/j.cmet.2015.09.026

2. Velloso LA, Araújo EP, de Souza CT. Diet-induced inflammation of the hypothalamus in obesity. Neuroimmunomodulation (2008) 15:189-93. doi:10.1159/000153423

3. Braun TP, Marks DL. Pathophysiology and treatment of inflammatory anorexia in chronic disease. J Cachexia Sarcopenia Muscle (2010) 1:135-45. doi:10.1007/s13539-010-0015-1

4. Dorfman MD, Thaler JP. Hypothalamic inflammation and gliosis in obesity. Curr Opin Endocrinol Diabetes Obes (2015) 22:325-30. doi:10.1097/ MED.0000000000000182

5. Cesar HC, Pisani LP. Fatty-acid-mediated hypothalamic inflammation and epigenetic programming. J Nutr Biochem (2017) 42:1-6. doi:10.1016/j. jnutbio.2016.08.008

6. Wisse BE, Schwartz MW. Does hypothalamic inflammation cause obesity? Cell Metab (2009) 10:241-2. doi:10.1016/j.cmet.2009.09.003

7. Le Thuc O, Rovère C. [Hypothalamic inflammation and energy balance deregulations: focus on chemokines]. Biol Aujourdhui (2016) 210(4):211-25. doi:10.1051/jbio/2016026

8. Wispelwey B, Lesse AJ, Hansen EJ, Scheld WM. Haemophilus influenzae lipopolysaccharide-induced blood brain barrier permeability during experimental meningitis in the rat. J Clin Invest (1988) 82:1339-46. doi:10.1172/ JCI113736

9. Layé S, Gheusi G, Cremona S, Combe C, Kelley K, Dantzer R, et al. Endogenous brain IL-1 mediates LPS-induced anorexia and hypothalamic cytokine expression. Am J Physiol Regul Integr Comp Physiol (2000) 279:R93-8.

10. Grossberg AJ, Scarlett JM, Marks DL. Hypothalamic mechanisms in cachexia. Physiol Behav (2010) 100:478-89. doi:10.1016/j.physbeh.2010.03.011

11. Wisse BE, Ogimoto K, Tang J, Harris MK, Raines EW, Schwartz MW. Evidence that lipopolysaccharide-induced anorexia depends upon central, rather than peripheral, inflammatory signals. Endocrinology (2007) 148:5230-7. doi:10.1210/en.2007-0394

12. Banisadr G, Quéraud-Lesaux F, Boutterin MC, Pélaprat D, Zalc B, Rostène W, et al. Distribution, cellular localization and functional role of CCR2 chemokine receptors in adult rat brain. J Neurochem (2002) 81:257-69. doi:10.1046/ j.1471-4159.2002.00809.x

13. van derMeer P,Ulrich AM, Gonźalez-ScaranoF,LaviE.Immunohistochemical analysis of CCR2, CCR3, CCR5, and CXCR4 in the human brain: potential mechanisms for HIV dementia. Exp Mol Pathol (2000) 69:192-201. doi:10.1006/exmp.2000.2336

14. Adler MW, Rogers TJ. Are chemokines the third major system in the brain? J Leukoc Biol (2005) 78:1204-9. doi:10.1189/jlb.0405222

15. Rostène W, Dansereau M-A, Godefroy D, Van Steenwinckel J, RéauxLe Goazigo A, Mélik-Parsadaniantz S, et al. Neurochemokines: a menage a trois providing new insights on the functions of chemokines in the central nervous system. JNeurochem (2011) 118:680-94. doi:10.1111/j.1471-4159.2011.07371.x

16. Guyon A, Banisadr G, Rovère C, Cervantes A, Kitabgi P, Melik Parsadaniantz S, et al. Complex effects of stromal cell-derived factor- $1 \alpha$ on melanin-concentrating hormone neuron excitability. Eur J Neurosci (2005) 21:701-10. doi:10.1111/j.1460-9568.2005.03890.x

17. Guyon A, Rovère C, Cervantes A, Allaeys I, Nahon JL. Stromal cell-derived factor-1alpha directly modulates voltage-dependent currents of the action

\section{FUNDING}

Studies from the authors' laboratory were funded by the CNRS, the Fondation pour la Recherche Médicale (DEQ20150331738 and DRM20101220421), and the French Government (National Research Agency, ANR) through the "Investments for the Future" LABEX SIGNALIFE: program reference \# ANR-11-LABX-0028-01.

potential in mammalian neuronal cells. J Neurochem (2005) 93:963-73 doi:10.1111/j.1471-4159.2005.03083.x

18. Callewaere C, Banisadr G, Desarménien MG, Mechighel P, Kitabgi P, Rostène WH, et al. The chemokine SDF-1/CXCL12 modulates the firing pattern of vasopressin neurons and counteracts induced vasopressin release through CXCR4. Proc Natl Acad Sci U S A (2006) 103:8221-6. doi:10.1073/ pnas.0602620103

19. Wong CJ. Involuntary weight loss. Med Clin (2014) 98:625-43. doi:10.1016/j. mona.2014.01.012

20. Vanderschueren S, Geens E, Knockaert D, Bobbaers H. The diagnostic spectrum of unintentional weight loss. Eur J Intern Med (2005) 16:160-4. doi:10.1016/j.ejim.2005.01.004

21. Tan BH, Fearon KC. Cachexia: prevalence and impact in medicine. Curr Opin Clin Nutr Metab Care (2008) 11:400-7. doi:10.1097/MCO.0b013e328300ecc1

22. Dantzer R. Cytokine, sickness behavior, and depression. Neurol Clin (2006) 24:441-60. doi:10.1016/j.ncl.2006.03.003

23. van Niekerk G, Isaacs AW, Nell T, Engelbrecht AM. Sickness-associated anorexia: Mother Nature's idea of immunonutrition? Mediators Inflamm (2016) 2016:8071539. doi:10.1155/2016/8071539

24. Mehler PS, Brown C. Anorexia nervosa - medical complications. J Eat Disord (2015) 3:11. doi:10.1186/s40337-015-0040-8

25. Muscaritoli M, Anker SD, Argiles J, Aversa Z, Bauer JM, Biolo G, et al. Consensus definition of sarcopenia, cachexia and pre-cachexia: joint document elaborated by special interest groups (SIG) "cachexia-anorexia in chronic wasting diseases" and "nutrition in geriatrics". Clin Nutr (2010) 29:154-9. doi:10.1016/j.clnu.2009.12.004

26. Müller TD, Perez-Tilve D, Tong J, Pfluger PT, Tschöp MH. Ghrelin and its potential in the treatment of eating/wasting disorders and cachexia. J Cachexia Sarcopenia Muscle (2010) 1:159-67. doi:10.1007/s13539-010-0012-4

27. Alexander C, Rietschel ET. Bacterial lipopolysaccharides and innate immunity. J Endotoxin Res (2001) 7:167-202. doi:10.1177/096805190100 70030101

28. Banks WA, Farr SA, La Scola ME, Morley JE. Intravenous human interleukinlalpha impairs memory processing in mice: dependence on blood-brain barrier transport into posterior division of the septum. J Pharmacol Exp Ther (2001) 299:536-41.

29. Kent S, Bluthé R-M, Kelley KW, Dantzer R. Sickness behavior as a new target for drug development. Trends Pharmacol Sci (1992) 13:24-8. doi:10.1016/0165-6147(92)90012-U

30. Spadaro F, Dunn AJ. Intracerebroventricular administration of interleukin-1 to mice alters investigation of stimuli in a novel environment. Brain Behav Immun (1990) 4:308-22. doi:10.1016/0889-1591(90)90034-N

31. Kent S, Kelley KW, Dantzer R. Effects of lipopolysaccharide on food-motivated behavior in the rat are not blocked by an interleukin-1 receptor antagonist. Neurosci Lett (1992) 145:83-6. doi:10.1016/0304-3940(92)90209-P

32. Kent S, Bluthé RM, Dantzer R, Hardwick AJ, Kelley KW, Rothwell NJ, et al. Different receptor mechanisms mediate the pyrogenic and behavioral effects of interleukin 1. Proc Natl Acad Sci U S A (1992) 89:9117-20. doi:10.1073/ pnas.89.19.9117

33. Johnson RW, Gheusi G, Segreti S, Dantzer R, Kelley KW. C3H/HeJ mice are refractory to lipopolysaccharide in the brain. Brain Res (1997) 752:219-26. doi:10.1016/S0006-8993(96)01454-0

34. Hopkins SJ, Rothwell NJ. Cytokines and the nervous system. I: expression and recognition. Trends Neurosci (1995) 18:83-8. doi:10.1016/0166-2236(95) 80029-2 
35. Rothwell NJ, Hopkins SJ. Cytokines and the nervous system II: actions and mechanisms of action. Trends Neurosci (1995) 18:130-6. doi:10.1016/ 0166-2236(95)93890-A

36. Licinio J, Wong ML. Pathways and mechanisms for cytokine signaling of the central nervous system. J Clin Invest (1997) 100:2941-7. doi:10.1172/ JCI119846

37. Sternberg EM. Neural-immune interactions in health and disease. J Clin Invest (1997) 100:2641-7. doi:10.1172/JCI119807

38. Mantovani G, Macciò A, Lai P, Massa E, Ghiani M, Santona MC. Cytokine involvement in cancer anorexia/cachexia: role of megestrol acetate and medroxyprogesterone acetate on cytokine downregulation and improvement of clinical symptoms. Crit Rev Oncog (1998) 9:99-106. doi:10.1615/ CritRevOncog.v9.i2.10

39. Haslett PA. Anticytokine approaches to the treatment of anorexia and cachexia. Semin Oncol (1998) 25:53-7.

40. Konsman JP, Parnet P, Dantzer R. Cytokine-induced sickness behaviour: mechanisms and implications. Trends Neurosci (2002) 25:154-9. doi:10.1016/ S0166-2236(00)02088-9.

41. Gelin J, Moldawer LL, Lönnroth C, Sherry B, Chizzonite R, Lundholm K. Role of endogenous tumor necrosis factor alpha and interleukin 1 for experimental tumor growth and the development of cancer cachexia. Cancer Res (1991) 51:415-21.

42. Matthys P, Billiau A. Cytokines and cachexia. Nutrition (1997) 13:763-70. doi:10.1016/S0899-9007(97)00185-8

43. Moldawer LL, Rogy MA, Lowry SF. The role of cytokines in cancer cachexia. JPEN J Parenter Enteral Nutr (1992) 16:43S-9S. doi:10.1177/014860719201 600602

44. Tisdale MJ. Biology of cachexia. J Natl Cancer Inst (1997) 89:1763-73. doi:10.1093/jnci/89.23.1763

45. Noguchi Y, Yoshikawa T, Matsumoto A, Svaninger G, Gelin J. Are cytokines possible mediators of cancer cachexia? Surg Today (1996) 26:467-75. doi:10.1007/BF00311551

46. Sherry BA, Gelin J, Fong Y, Marano M, Wei H, Cerami A, et al. Anticachectin/ tumor necrosis factor-alpha antibodies attenuate development of cachexia in tumor models. FASEB J (1989) 3:1956-62.

47. Laviano A, Gleason JR, Meguid MM, Yang ZJ, Cangiano C, Rossi Fanelli F. Effects of intra-VMN mianserin and IL-1ra on meal number in anorectic tumor-bearing rats. J Investig Med (2000) 48:40-8.

48. Scarlett JM, Jobst EE, Enriori PJ, Bowe DD, Batra AK, Grant WF, et al. Regulation of central melanocortin signaling by interleukin-1 beta. Endocrinology (2007) 148:4217-25. doi:10.1210/en.2007-0017

49. Arruda AP, Milanski M, Coope A, Torsoni AS, Ropelle E, Carvalho DP, et al. Low-grade hypothalamic inflammation leads to defective thermogenesis, insulin resistance, and impaired insulin secretion. Endocrinology (2011) 152:1314-26. doi:10.1210/en.2010-0659

50. Ropelle ER, Pauli JR, Zecchin KG, Ueno M, de Souza CT, Morari J, et al. A central role for neuronal adenosine 5'-monophosphate-activated protein kinase in cancer-induced anorexia. Endocrinology (2007) 148:5220-9. doi:10.1210/en.2007-0381

51. DeBoer MD, Zhu XX, Levasseur P, Meguid MM, Suzuki S, Inui A, et al. Ghrelin treatment causes increased food intake and retention of lean body mass in a rat model of cancer cachexia. Endocrinology (2007) 148:3004-12. doi:10.1210/en.2007-0016

52. Ueta Y, Hashimoto H, Onuma E, Takuwa Y, Ogata E. Hypothalamic neuropeptides and appetite response in anorexia-cachexia animal. Endocr J (2007) 54:831-8. doi:10.1507/endocrj.KR-111

53. Gay NJ, Gangloff M, Weber AN. Toll-like receptors as molecular switches. Nat Rev Immunol (2006) 6:693-8. doi:10.1038/nri1916

54. Lien E, Means TK, Heine H, Yoshimura A, Kusumoto S, Fukase K, et al. Toll-like receptor 4 imparts ligand-specific recognition of bacterial lipopolysaccharide. J Clin Invest (2000) 105:497-504. doi:10.1172/JCI8541

55. Chakravarty S, Herkenham M. Toll-like receptor 4 on nonhematopoietic cells sustains CNS inflammation during endotoxemia, independent of systemic cytokines. J Neurosci (2005) 25:1788-96. doi:10.1523/JNEUROSCI.426804.2005

56. Lehnardt S, Lachance C, Patrizi S, Lefebvre S, Follett PL, Jensen FE, et al. The toll-like receptor TLR4 is necessary for lipopolysaccharide-induced oligodendrocyte injury in the CNS. J Neurosci (2002) 22:2478-86.
57. Hines DJ, Choi HB, Hines RM, Phillips AG, MacVicar BA. Prevention of LPS-induced microglia activation, cytokine production and sickness behavior with TLR4 receptor interfering peptides. PLoS One (2013) 8:e60388. doi:10.1371/journal.pone.0060388

58. Reis WL, Yi C-X, Gao Y, Tschöp MH, Stern JE. Brain innate immunity regulates hypothalamic arcuate neuronal activity and feeding behavior Endocrinology (2015) 156:1303-15. doi:10.1210/en.2014-1849

59. Gayle D, Ilyin SE, Plata-Salamán CR. Feeding status and bacterial LPSinduced cytokine and neuropeptide gene expression in hypothalamus. Am J Physiol (1999) 277:R1188-95.

60. Ogimoto K, Harris MK, Wisse BE. MyD88 is a key mediator of anorexia, but not weight loss, induced by lipopolysaccharide and interleukin-1 beta. Endocrinology (2006) 147:4445-53. doi:10.1210/en.2006-0465

61. Sergeyev V, Broberger C, Hökfelt T. Effect of LPS administration on the expression of POMC, NPY, galanin, CART and MCH mRNAs in the rat hypothalamus. Brain Res Mol Brain Res (2001) 90:93-100. doi:10.1016/ S0169-328X(01)00088-2

62. Jang P-G, Namkoong C, Kang GM, Hur M-W, Kim S-W, Kim GH, et al. NF-kappaB activation in hypothalamic pro-opiomelanocortin neurons is essential in illness- and leptin-induced anorexia. J Biol Chem (2010) 285:9706-15. doi:10.1074/jbc.M109.070706

63. Jin S, Kim JG, Park JW, Koch M, Horvath TL, Lee BJ. Hypothalamic TLR2 triggers sickness behavior via a microglia-neuronal axis. Sci Rep (2016) 6:29424. doi:10.1038/srep29424

64. Murray C, Griffin ÉW, O'Loughlin E, Lyons A, Sherwin E, Ahmed S, et al. Interdependent and independent roles of type I interferons and IL-6 in innate immune, neuroinflammatory and sickness behaviour responses to systemic poly I:C. Brain Behav Immun (2015) 48:274-86. doi:10.1016/j. bbi.2015.04.009

65. Dwarkasing JT, Boekschoten MV, Argilès JM, van Dijk M, Busquets S, Penna F, et al. Differences in food intake of tumour-bearing cachectic mice are associated with hypothalamic serotonin signalling. J Cachexia Sarcopenia Muscle (2015) 6:84-94. doi:10.1002/jcsm.12008

66. Laviano A, Inui A, Meguid MM, Molfino A, Conte C, Rossi Fanelli F. NPY and brain monoamines in the pathogenesis of cancer anorexia. Nutrition (2008) 24:802-5. doi:10.1016/j.nut.2008.06.005

67. Meguid MM, Ramos EJB, Laviano A, Varma M, Sato T, Chen C, et al. Tumor anorexia: effects on neuropeptide $\mathrm{Y}$ and monoamines in paraventricular nucleus. Peptides (2004) 25:261-6. doi:10.1016/j.peptides.2004.01.012

68. Dwarkasing JT, Witkamp RF, Boekschoten MV, Laak MC, Heins MS, Norren K. Increased hypothalamic serotonin turnover in inflammation-induced anorexia. BMC Neurosci (2016) 17:26. doi:10.1186/s12868-016-0260-0

69. Plata-Salamán CR, Borkoski JP. Chemokines/intercrines and central regulation of feeding. Am J Physiol (1994) 266:R1711-5.

70. Le Thuc O, Cansell C, Bourourou M, Denis RG, Stobbe K, Devaux N, et al. Central CCL2 signaling onto $\mathrm{MCH}$ neurons mediates metabolic and behavioral adaptation to inflammation. EMBO Rep (2016) 17:1738-52. doi:10.15252/embr.201541499

71. Cazareth J, Guyon A, Heurteaux C, Chabry J, Petit-Paitel A. Molecular and cellular neuroinflammatory status of mouse brain after systemic lipopolysaccharide challenge: importance of CCR2/CCL2 signaling. J Neuroinflammation (2014) 11:132. doi:10.1186/1742-2094-11-132

72. Conductier G, Blondeau N, Guyon A, Nahon J-L, Rovère C. The role of monocyte chemoattractant protein MCP1/CCL2 in neuroinflammatory diseases. J Neuroimmunol (2010) 224:93-100. doi:10.1016/j.jneuroim.2010.05.010

73. Thompson WL, Karpus WJ, Van Eldik LJ. MCP-1-deficient mice show reduced neuroinflammatory responses and increased peripheral inflammatory responses to peripheral endotoxin insult. J Neuroinflammation (2008) 5:35. doi:10.1186/1742-2094-5-35

74. Nahon JL. The melanocortins and melanin-concentrating hormone in the central regulation of feeding behavior and energy homeostasis. C R Biol (2006) 329:623-38; discussion 653-5. doi:10.1016/j.crvi.2006.03.021

75. Morari J, Anhe GF, Nascimento LF, de Moura RF, Razolli D, Solon C, et al. Fractalkine (CX3CL1) is involved in the early activation of hypothalamic inflammation in experimental obesity. Diabetes (2014) 63:3770-84. doi:10.2337/db13-1495

76. Poon K, Barson JR, Ho HT, Leibowitz SF. Relationship of the chemokine, CXCL12, to effects of dietary fat on feeding-related behaviors and 
hypothalamic neuropeptide systems. Front Behav Neurosci (2016) 10:51. doi:10.3389/fnbeh.2016.00051

77. Dalmas E, Rouault C, Abdennour M, Rovere C, Rizkalla S, Bar-Hen A, et al. Variations in circulating inflammatory factors are related to changes in calorie and carbohydrate intakes early in the course of surgery-induced weight reduction. Am J Clin Nutr (2011) 94:450-8. doi:10.3945/ajcn.111.013771

78. Le Thuc O, Blondeau N, Rouaud F, Poitou C, Clement K, Guyon A, et al. Role of the chemokine RANTES/CCL5 in the establishment of high-fat dietinduced obesity in mice. 9th FENS Forum of Neuroscience. Milan (2014).

79. Gregor MF, Hotamisligil GS. Inflammatory mechanisms in obesity. Annu Rev Immunol (2011) 29:415-45. doi:10.1146/annurev-immunol-031210-101322

80. Williams EP, Mesidor M, Winters K, Dubbert PM, Wyatt SB. Overweight and obesity: prevalence, consequences, and causes of a growing public health problem. Curr Obes Rep (2015) 4:363-70. doi:10.1007/s13679-015-0169-4

81. Smith KB, Smith MS. Obesity statistics. Prim Care (2016) 43:121-35,ix. doi:10.1016/j.pop.2015.10.001

82. Thaler JP, Yi C-X, Schur EA, Guyenet SJ, Hwang BH, Dietrich MO, et al. Obesity is associated with hypothalamic injury in rodents and humans. J Clin Invest (2012) 122:153-62. doi:10.1172/JCI59660

83. De Souza CT, Araujo EP, Bordin S, Ashimine R, Zollner RL, Boschero AC, et al. Consumption of a fat-rich diet activates a proinflammatory response and induces insulin resistance in the hypothalamus. Endocrinology (2005) 146:4192-9. doi:10.1210/en.2004-1520

84. Kleinridders A, Schenten D, Konner AC, Belgardt BF, Mauer J, Okamura T, et al. MyD88 signaling in the CNS is required for development of fatty acid-induced leptin resistance and diet-induced obesity. Cell Metab (2009) 10:249-59. doi:10.1016/j.cmet.2009.08.013

85. Valdearcos M, Robblee MM, Benjamin DI, Nomura DK, Xu AW, Koliwad SK. Microglia dictate the impact of saturated fat consumption on hypothalamic inflammation and neuronal function. Cell Rep (2014) 9:2124-38. doi:10.1016/j.celrep.2014.11.018

86. Zhang X, Zhang G, Zhang H, Karin M, Bai H, Cai D. Hypothalamic IKKbeta/ NF-kappaB and ER stress link overnutrition to energy imbalance and obesity. Cell (2008) 135:61-73. doi:10.1016/j.cell.2008.07.043

87. Posey KA, Clegg DJ, Printz RL, Byun J, Morton GJ, Vivekanandan-Giri A, et al. Hypothalamic proinflammatory lipid accumulation, inflammation, and insulin resistance in rats fed a high-fat diet. Am J Physiol Endocrinol Metab (2009) 296:E1003-12. doi:10.1152/ajpendo.90377.2008

88. Grayson BE, Levasseur PR, Williams SM, Smith MS, Marks DL, Grove KL. Changes in melanocortin expression and inflammatory pathways in fetal offspring of nonhuman primates fed a high-fat diet. Endocrinology (2010) 151:1622-32. doi:10.1210/en.2009-1019

89. Holland WL, Bikman BT, Wang L-P, Yuguang G, Sargent KM, Bulchand S, et al. Lipid-induced insulin resistance mediated by the proinflammatory receptor TLR4 requires saturated fatty acid-induced ceramide biosynthesis in mice. J Clin Invest (2011) 121:1858-70. doi:10.1172/JCI43378

90. Maric T, Woodside B, Luheshi GN. The effects of dietary saturated fat on basal hypothalamic neuroinflammation in rats. Brain Behav Immun (2014) 36:35-45. doi:10.1016/j.bbi.2013.09.011

91. Morselli E, Fuente-Martin E, Finan B, Kim M, Frank A, Garcia-Caceres C, et al. Hypothalamic PGC- $1 \alpha$ protects against high-fat diet exposure by regulating ER $\alpha$. Cell Rep (2014) 9:633-45. doi:10.1016/j.celrep.2014.09.025

92. Weissmann L, Quaresma PGF, Santos AC, de Matos AHB, Pascoal VDÁB, Zanotto TM, et al. IKKe is key to induction of insulin resistance in the hypothalamus, and its inhibition reverses obesity. Diabetes (2014) 63:3334-45. doi:10.2337/db13-1817

93. Dalvi PS, Chalmers JA, Luo V, Han DY, Wellhauser L, Liu Y, et al. High fat induces acute and chronic inflammation in the hypothalamus: effect of highfat diet, palmitate and TNF-alpha on appetite-regulating NPY neurons. Int J Obes (Lond) (2017) 41:149-58. doi:10.1038/ijo.2016.183

94. Zhang W, Hu X, Yang W, Gao Y, Chen J. Omega-3 polyunsaturated fatty acid supplementation confers long-term neuroprotection against neonatal hypoxic-ischemic brain injury through anti-inflammatory actions. Stroke (2010) 41:2341-7. doi:10.1161/STROKEAHA.110.586081

95. Buckley JD, Howe PRC. Long-chain omega-3 polyunsaturated fatty acids may be beneficial for reducing obesity - a review. Nutrients (2010) 2:1212-30. doi:10.3390/nu2121212
96. Cintra DE, Ropelle ER, Moraes JC, Pauli JR, Morari J, de Souza CT, et al. Unsaturated fatty acids revert diet-induced hypothalamic inflammation in obesity. PLoS One (2012) 7:e30571. doi:10.1371/journal.pone.0030571

97. Oliveira V, Marinho R, Vitorino D, Santos GA, Moraes JC, Dragano N, et al. Diets containing alpha-linolenic (omega 3) or oleic (omega 9) fatty acids rescues obese mice from insulin resistance. Endocrinology (2015) 156:4033-46. doi:10.1210/en.2014-1880

98. Gao Y, Ottaway N, Schriever SC, Legutko B, García-Cáceres C, de la Fuente E, et al. Hormones and diet, but not body weight, control hypothalamic microglial activity. Glia (2014) 62:17-25. doi:10.1002/ glia. 22580

99. Fantuzzi G, Faggioni R. Leptin in the regulation of immunity, inflammation, and hematopoiesis. J Leukoc Biol (2000) 68:437-46.

100. Hotamisligil GS. Endoplasmic reticulum stress and the inflammatory basis of metabolic disease. Cell (2010) 140:900-17. doi:10.1016/j.cell.2010. 02.034

101. Purkayastha S, Zhang H, Zhang G, Ahmed Z, Wang Y, Cai D. Neural dysregulation of peripheral insulin action and blood pressure by brain endoplasmic reticulum stress. Proc Natl Acad Sci U S A (2011) 108:2939-44. doi:10.1073/ pnas. 1006875108

102. Matsuzawa-Nagata N, Takamura T, Ando H, Nakamura S, Kurita S, Misu H, et al. Increased oxidative stress precedes the onset of high-fat diet-induced insulin resistance and obesity. Metabolism (2008) 57:1071-7. doi:10.1016/j. metabol.2008.03.010

103. Leloup C, Casteilla L, Carrière A, Galinier A, Benani A, Carneiro L, et al. Balancing mitochondrial redox signaling: a key point in metabolic regulation. Antioxid Redox Signal (2011) 14:519-30. doi:10.1089/ars.2010.3424

104. Colombani A-L, Carneiro L, Benani A, Galinier A, Jaillard T, Duparc T, et al. Enhanced hypothalamic glucose sensing in obesity: alteration of redox signaling. Diabetes (2009) 58:2189-97. doi:10.2337/db09-0110

105. Butler D, Bahr BA. Oxidative stress and lysosomes: CNS-related consequences and implications for lysosomal enhancement strategies and induction of autophagy. Antioxid Redox Signal (2006) 8:185-96. doi:10.1089/ ars.2006.8.185

106. Yorimitsu T, Nair U, Yang Z, Klionsky DJ. Endoplasmic reticulum stress triggers autophagy. J Biol Chem (2006) 281:30299-304. doi:10.1074/jbc. M607007200

107. Douglass JD, Dorfman MD, Fasnacht R, Shaffer LD, Thaler JP. Astrocyte IKKbeta/NF-kappaB signaling is required for diet-induced obesity and hypothalamic inflammation. Mol Metab (2017) 6:366-73. doi:10.1016/j. molmet.2017.01.010

108. Benzler J, Ganjam GK, Pretz D, Oelkrug R, Koch CE, Legler K, et al. Central inhibition of IKKbeta/NF-kappaB signaling attenuates high-fat diet-induced obesity and glucose intolerance. Diabetes (2015) 64:2015-27. doi:10.2337/ db14-0093

109. Barreto-Vianna AR, Aguila MB, Mandarim-de-Lacerda CA. Effects of liraglutide in hypothalamic arcuate nucleus of obese mice. Obesity (Silver Spring) (2016) 24:626-33. doi:10.1002/oby.21387

110. Naznin F, Sakoda H, Okada T, Tsubouchi H, Waise TM, Arakawa K, et al. Canagliflozin, a sodium glucose cotransporter 2 inhibitor, attenuates obesity-induced inflammation in the nodose ganglion, hypothalamus, and skeletal muscle of mice. Eur J Pharmacol (2017) 794:37-44. doi:10.1016/j. ejphar.2016.11.028

111. Oh-I S, Thaler JP, Ogimoto K, Wisse BE, Morton GJ, Schwartz MW. Central administration of interleukin-4 exacerbates hypothalamic inflammation and weight gain during high-fat feeding. Am J Physiol Endocrinol Metab (2010) 299:E47-53. doi:10.1152/ajpendo.00026.2010

112. André C, Guzman-Quevedo O, Rey C, émus-Borel JR, Clark S, CastellanosJankiewicz A, et al. Inhibiting microglia expansion prevents diet-induced hypothalamic and peripheral inflammation. Diabetes (2017) 66:908-19. doi: $10.2337 / \mathrm{db} 16-0586$

113. Guyon A, Rovere C, Cervantes A, Allaeys I, Nahon JL. Stromal cell-derived factor-1alpha directly modulates voltage-dependent currents of the action potential in mammalian neuronal cells. JNeurochem (2005) 93:963-73. doi:10.1111/j.1471-4159.2005.03083.x

114. Skrzydelski D, Guyon A, Dauge V, Rovere C, Apartis E, Kitabgi P, et al. The chemokine stromal cell-derived factor-1/CXCL12 activates the nigrostriatal 
dopamine system. J Neurochem (2007) 102:1175-83. doi:10.1111/j.14714159.2007.04639.x

115. Keophiphath M, Rouault C, Divoux A, Clement K, Lacasa D. CCL5 promotes macrophage recruitment and survival in human adipose tissue. Arterioscler Thromb Vasc Biol (2009) 30:39-45. doi:10.1161/atvbaha.109. 197442

116. Wu H, Ghosh S, Perrard XD, Feng L, Garcia GE, Perrard JL, et al. T-cell accumulation and regulated on activation, normal $\mathrm{T}$ cell expressed and secreted upregulation in adipose tissue in obesity. Circulation (2007) 115:1029-38. doi:10.1161/circulationaha.106.638379
Conflict of Interest Statement: The authors declare that the research was conducted in the absence of any commercial or financial relationships that could be construed as a potential conflict of interest.

Copyright $\odot 2017$ Le Thuc, Stobbe, Cansell, Nahon, Blondeau and Rovère. This is an open-access article distributed under the terms of the Creative Commons Attribution License (CC BY). The use, distribution or reproduction in other forums is permitted, provided the original author(s) or licensor are credited and that the original publication in this journal is cited, in accordance with accepted academic practice. No use, distribution or reproduction is permitted which does not comply with these terms. 